\title{
INDUCTION OF METAMORPHOSIS BY BACTERIA AND IONS IN THE PLANULAE OF HYDRACTINIA ECHINATA; AN APPROACH TO THE MODE OF ACTION
}

\section{$\operatorname{AUTHOR}(\mathrm{S})$ :}

Muller, W. A.

\section{CITATION:}

Muller, W. A.. INDUCTION OF METAMORPHOSIS BY BACTERIA AND IONS IN THE PLANULAE OF HYDRACTINIA ECHINATA; AN APPROACH TO THE MODE OF ACTION. PUBLICATIONS OF THE SETO MARINE BIOLOGICAL LABORATORY 1973, 20: 195-208

\section{ISSUE DATE:}

\section{3-12-19}

URL:

http://hdl.handle.net/2433/175777

RIGHT: 


\title{
INDUCTION OF METAMORPHOSIS BY BACTERIA AND IONS \\ IN THE PLANULAE OF HYDRACTINIA ECHINATA; AN APPROACH TO THE MODE OF ACTION
}

\author{
W.A. MÜLLER \\ Zoologisches Institut der Technischen Universität, \\ Pockelsstrasse 10a, 33 Braunschweig, Germany \\ With 7 Text-figures
}

The phenomena and problems which I want to bring to your attention do not only concern the physiology of hydroid development. They are also of ecological significance. I shall, however, restrict my report to those aspects which may elucidate the complex events initiating and regulating the morphogenetic phenomenon of metamorphosis.

Hydractinia echinata is a polymorphic colony normally growing on shells inhabited by hermit crabs. The sexual products mature within the gonophores of blastostyles (=gonozoids). They are liberated into the sea in the early morning. Spawning follows an endogen circadian rhythm which is synchronized by the lightdark cycle (for details see MüLLER, 1961, 1964, 1969). The fertilized eggs, within 48 hrs, give rise to the planulae which are ready to settle on any substratum and to metamorphose as shown in Fig. 1.

The larva attaches to the substratum with its anterior pole and retracts its tail. This retraction and the flattening of the anterior lobe give rise to a disc-shaped appearance of the animal. The contraction is accompanied by secretion of slime and by a slowing down and finally by the stopping of the ciliary beat. Subsequently the apical annulated part of the disc slowly emerges to form a truncated cone. This expanding cone develops into the hydranth of the primary polyp, whereas the flat basal part will grow stolons.

It is quite easy to procure millions of planulae (for methods see MüLLER, 1969; Müller and SPINdler, 1972; SPIndler and Müller, 1972). But none of these larvae will undergo metamorphosis when kept in clean seawater. No spontaneous transformation will occur until the larvae eventually paralyse after about 4 weeks. What could be the cause of this failure? The planula is the only free living stage. This free moving larva has to find an environment suited to its adult life. But how can the planula comply with such a task? Its sensory equipment is very limited. The larva, therefore, depends on distinct, precisely defined key stimuli to find an environment in which to survive. Of what kind are these environmental stimuli?

The stimulus initiating metamorphosis emanates from certain marine bacteria. 
These bacteria release under well defined conditions a substance which directly induces metamorphosis by influencing the physicochemical state of the larval cell membranes.

Let us explain and discuss this statement in more detail. To avoid misunderstandings some points should be emphasized from the outset: Firstly, the bacteria do not act in an indirect way by conferring some kind of attractiveness upon the substratum or by altering its physicochemical properties. When exposed to the bacterial stimulus the planulae will undergo metamorphosis even without any support to settle on, thus giving origin to free floating polyps. Secondly, the inducing ability is not an unspecific feature common to all bacteria. Only a limited number of species or
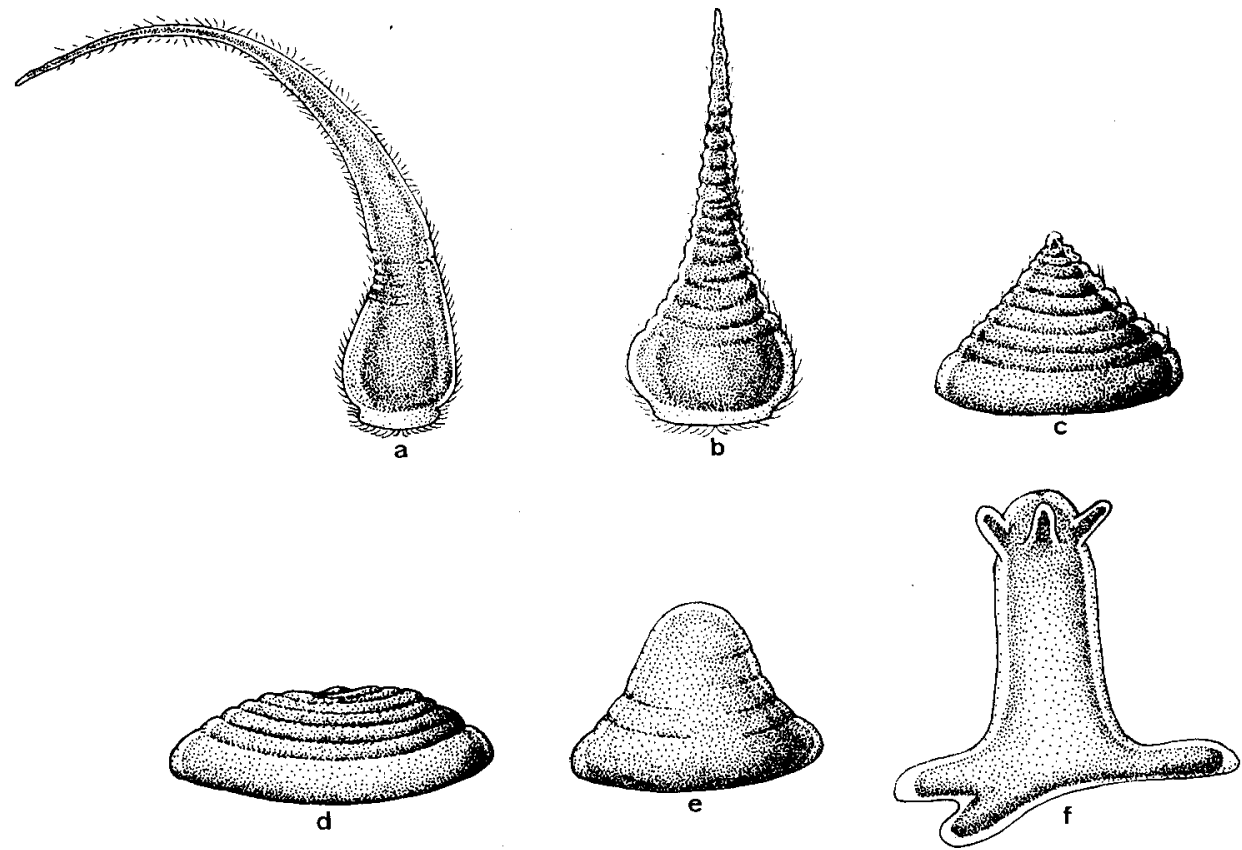

Fig. 1. Metamorphosis of the planula larva into a primary polyp.

strains which are regularly found in the natural habitat of the hydroid are able to exert the relevant influence. Moreover, these bacteria become effective only under defined breeding conditions.

The discovery of this phenomenon had its origin in a casual observation. When exposed to extracts of Hydractinia eggs the larvae went into metamorphosis after about $24 \mathrm{hrs}$. Extracts of meat but not of algae were equally effective. Apparently, the meat extracts contained a factor essential for the larvae in order to start transformation. However, all efforts to isolate this supposed essential substance were unsuccessful when the bioassay of the fractions was carried out under sterile precautions. Hence the question: was the inducing effect caused by a microbial contamination rather than by the extract itself? 
This was indeed the case. The detailed proofs of this statement have already been published (MüLLER, 1969). Therefore, only one additional experiment may be outlined. This experiment simultaneously demonstrates some of the prerequisites which must be satisfied in order to bring the bacteria into the effective state.

Very diluted extracts of meat containing about 100-200 $\mu \mathrm{g}$ protein per ml were inoculated with bacteria taken from shells of hermit crabs. This broth medium was well aerated and incubated until the optical density at $540 \mathrm{~nm}$ indicated the attainment of the stationary growth phase. At different times of the bacterial growth samples of the bacterial suspension, of the pure culture medium, and of pure bacteria were prepared for testing. For this purpose, samples each containing the same number of bacteria were collected on membrane filters by filtration. The bacterial film was overlaid with $10 \mathrm{ml}$ of seawater. 100-300 larvae were added to the film as well as to $10 \mathrm{ml}$ of the filtrated medium and to $10 \mathrm{ml}$ of the original bacterial suspension. The suspension and the medium cleared of bacteria were mixed with antibiotics. The

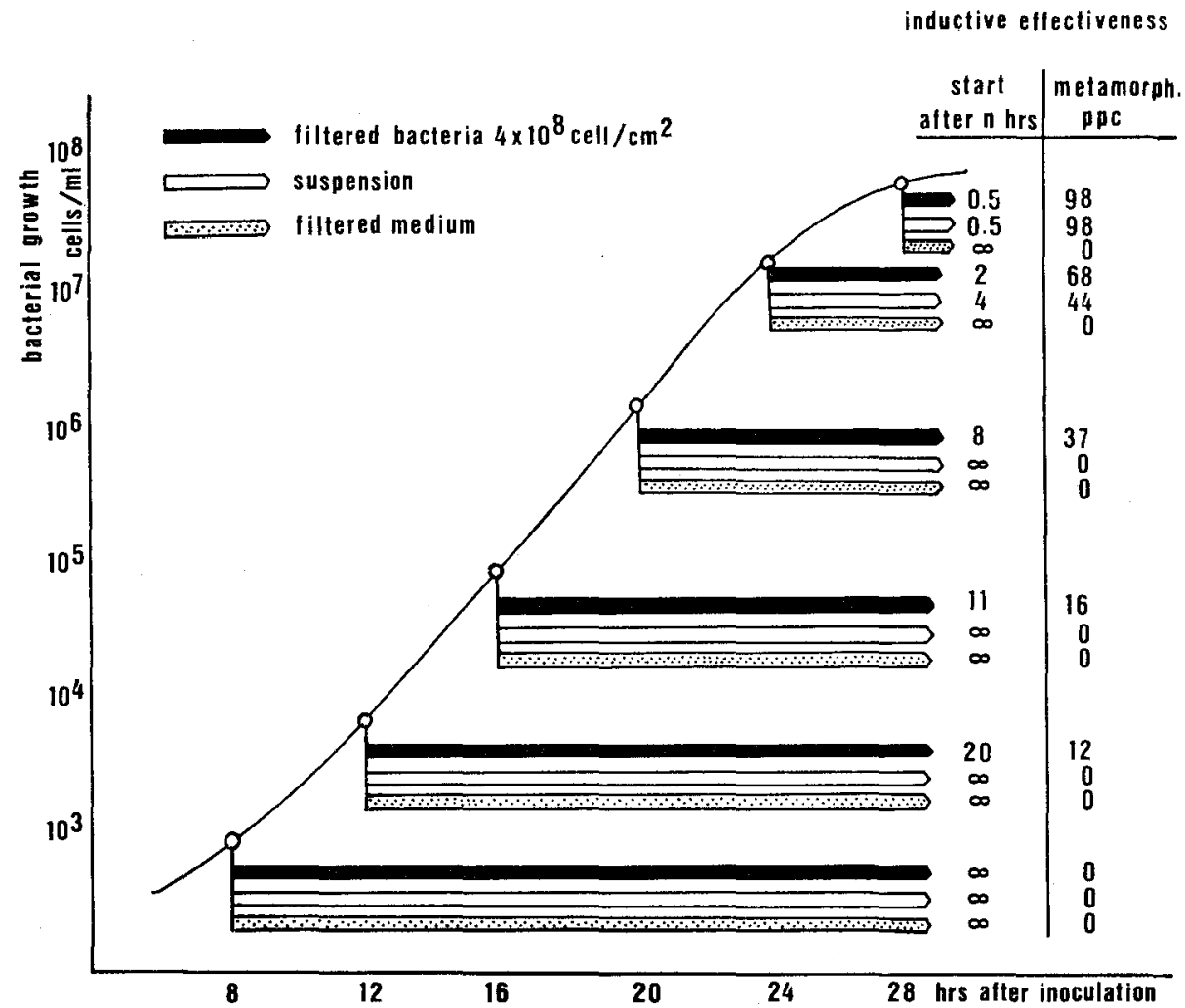

Fig. 2. Illustration of an experiment giving evidence that bacteria are the source of the inducing influence and demonstrating that the inductive power becomes manifest at the end of logarithmic growth. 
results are illustrated in Fig. 2.

The incubation medium deprived of bacteria at no time exhibited any inductive power. When harvested $8 \mathrm{hrs}$ after inoculation the suspension and the isolated bacteria were ineffective as well. The second sample of bacteria applied to on a membrane filter $4 \mathrm{hrs}$ later caused $12 \%$ of the larvae to engage in metamorphosis but transformation did not start earlier than $20 \mathrm{hrs}$ after addition of the larvae. The suspension mixed with antibiotics still remained ineffective. The inducing capacity of the further samples increased progressively, although the density of the bacterial layers on the membranes was kept constant. The percentage of planulae undergoing metamorphosis increased and transformation started earlier. The suspensions, however, which had been mixed with antibiotics just before testing, trailed behind though their increasing bacterial content now equalled or even surpassed the number of germs on the membranes. In the last samples taken $28 \mathrm{hrs}$ after inoculation metamorphosis started already within 30-60 min and almost $100 \%$ of the larvae went into metamorphosis. This applies to both the bacterial film and the suspension. The attainment of the optimal effectiveness was correlated with the end of exponential growth. Once the microbes have reached this phase of growth addition of antibiotics did not prevent or even delay the onset of metamorphosis.

I have succeeded in isolating several strains of effective bacteria from the bulk of unsuitable germs. With such pure cultures I have shown that the inductive power depends on the type of bacterium, the density per unit area, the growth phase at the time of contact, and the culture medium used. In order for the bacteria to produce the desired optimal effect they must not be bred on agar but should be suspended in low concentrations of meat extract under aerobic conditions. The inducing capacity will not become manifest until logarithmic growth turns into the stationary phase. Furthermore, the inductive power of stationary cells is enhanced by their transfer into seawater lacking nutritive sources.

This experience appeared to me somewhat mysterious but they have been significant hints for microbiologists to put me on the right track to trace the nature of the inducing stimulus.

It is known to microbiologists (e.g. NEU and Chou, 1967; KraEpelin, 1972; HEINZELMANN et al., 1972) that stationary cells, especially when transferred into a fresh minimal medium, release a variety of substances with various physiological activities. These substances, covered with the scarcely adequate term "leakage" products, are often excreted rhythmically. Cyclic-AMP and folic acid, the attractive stimuli for the collective amoebae, belong to this category of microbial products. Is the relevant agent inducing metamorphosis a similar secretory product with hormonelike properties?

At first, this did not seem to be the case. Removal of the microbes by filtration rendered the medium entirely ineffective. Moreover, when the larvae were encircled by a ringlike layer of bacteria the only larvae that stopped moving and engaged in 
metamorphosis were those which came in close contact to the microbes. Hence, the inductive impulse appeared to be transferred by a contact dependent event. However, microscopic examinations revealed that the bacteria exert their influence over at least a short distance. Their direct approach is prevented by the water current which the cilia produce as well as by the protective coat of slime covering the larval epithelium.

On the other hand, the inductive impulse did not penetrate dialysis membranes, provided membranes with normal pore sizes had been selected. I must emphasize: "with normal pore sizes." Indeed, if one chooses membranes penetrable for macromolecules and if one ensures a quick exchange between the chambers of the apparatus, the inductive factor will eventually pass through the membranes.

Hence, the stimulus seems to be of a chemical nature. But how do we prove this definitively, how do we isolate the substance? Extracts of bacteria turned out to be highly toxic to the larvae. As mentioned before, the medium itself from which the bacterial cells had been removed, is entirely ineffective. Killed cells are ineffective as well. The concentration of the substance apparently surpasses the threshold level only in the close boundary zone of living cells. Therefore, we must find a method of stimulating the bacteria to liberate greater amounts of the relevant substance.

Here again, we may profit from the experience of microbiologists. The release of surface bound enzymes and the secretion of the so-called leakage products can be enhanced by submitting the microbes to a process of osmotic shock (LewIS and PHAFF, 1964; Neu and Chou, 1967; Heppel, 1967; Buckmire and MaCLeOd, 1970; KraePELIN, 1972).

Such a procedure, indeed, brought us the desired success: Stationary-phase cells were collected by centrifugation and resuspended in $1.12 \mathrm{M} \mathrm{NaCl}$, that is a medium of high osmotic pressure and lacking divalent cations. EDTA was added to give a final concentration of $0.1 \mathrm{mM}$. After a short period of treatment the cells were collected again and subsequently submitted to a shock fluid containing only $0.01 \mathrm{M}$ $\mathrm{NaCl}$. The suspension was incubated for $2 \mathrm{hrs}$. The bacteria were then removed by centrifugation. They remained viable as proved by plating serially diluted samples on agar. However, due to this shock treatment the bacteria lost their inductive capacity. The inducing principle was now present in the supernatant. This leakage fluid was freed from any remaining bacterial contamination by sterile filtration, concentrated in a rotavapor and, after adjustment of the osmotic value, tested in serial dilutions and varying periods of application. At proper dosages $100 \%$ transformations were achieved almost every time.

When elaborating this process of osmotic shock I had to take care that the bacteria retained their harmful endotoxins. However, the leakage solution obtained by this procedure still contains some toxic substances which may sometimes reduce or mask the inducing power. Most of these toxins can be removed by simple techniques. The inducer can, at least in part, be precipitated with acetone together with proteins and reextracted from the precipitate with chloroform-methanol $(1: 1)$. More conveniently, 
the inducer can be extracted directly from the watery leakage fluid with chloroform and concentrated by lyophilization.

The lyophilized sample causes the larvae to undergo metamorphosis completely and instantaneously. The time of application, however, must be restricted to about $4 \mathrm{hrs}$ because transformation will be completed only in the absence of the inducer.

Our trials to purify the substance by chromatographic methods are unfortunately impeded on account of its instability. The inducer proved to be rather quickly inactivated by UV, warmth and oxygen. Experiments to determine the chemical class by enzymatic degradation gave conflicting results. The chemical nature of the principle, therefore, remains to be identified.

At any rate, the biologist may be interested more in the physiological effects brought about by the agent than in its chemical composition. These effects will be the subject of the remaining sections of this paper. The attempt to determine the mode of action exerted by the bacterial inducer has to take at least two observations into consideration:

Firstly, there exists no limited receptory field to receive the inductive stimulus. This statement is based upon a series of transection experiments (see SPINDLER and MüLLER, 1972). These experiments revealed that every part of the fragmented larva is able to respond to inductive stimuli with transformation. The isolated fragments develop into parts of polyps according to their prospective fate. The relevant conclusion one can reach from these findings is that the whole surface of the planula is susceptible to the inductive impulse.

Secondly, the inductive power of the microbial agent is imitated by certain monovalent cations.

What is the significance of these ions? How are they involved? The first reliable reaction indicating the onset of metamorphosis is the stop of the ciliary beat. Attempting to prove the significance of this probably only concomitant symptom we tried to stop the ciliary movement by applying lithium, known to inhibit the contractile system of cilia. Surprisingly, the lithium-ion leads not only to a stoppage of the ciliary beat but also to a rapid and complete transformation. This suggested that the ciliary apparatus might be the primary target. This original assumption, however, has now given place to the realisation that the stop of the ciliary beat is only a secondary consequence of events taking place in the cell membrane.

Lithium is not the only element that will exert an inducing influence. Other monovalent cations are powerful inducers as well: rubidium, caesium and an increased concentration of external potassium. All these ions must be applied for a limited time (2-4 hrs). Metamorphosis will only be completed after the larvae have been put back into normal seawater. This means that the ionic pulse acts only as a stimulating trigger impulse.

A first hint concerning the mode of action can be derived from dosage-response curves. When, at constant periods of application, the concentration of the ions is 
plotted against their effectiveness the line for caesium follows a common sigmoid-like curve. The lines for the other cations display an optimum peak (Fig. 3). Let us firstly discuss the probable significance of the optimum which is most sharply pronounced in the case of potassium:

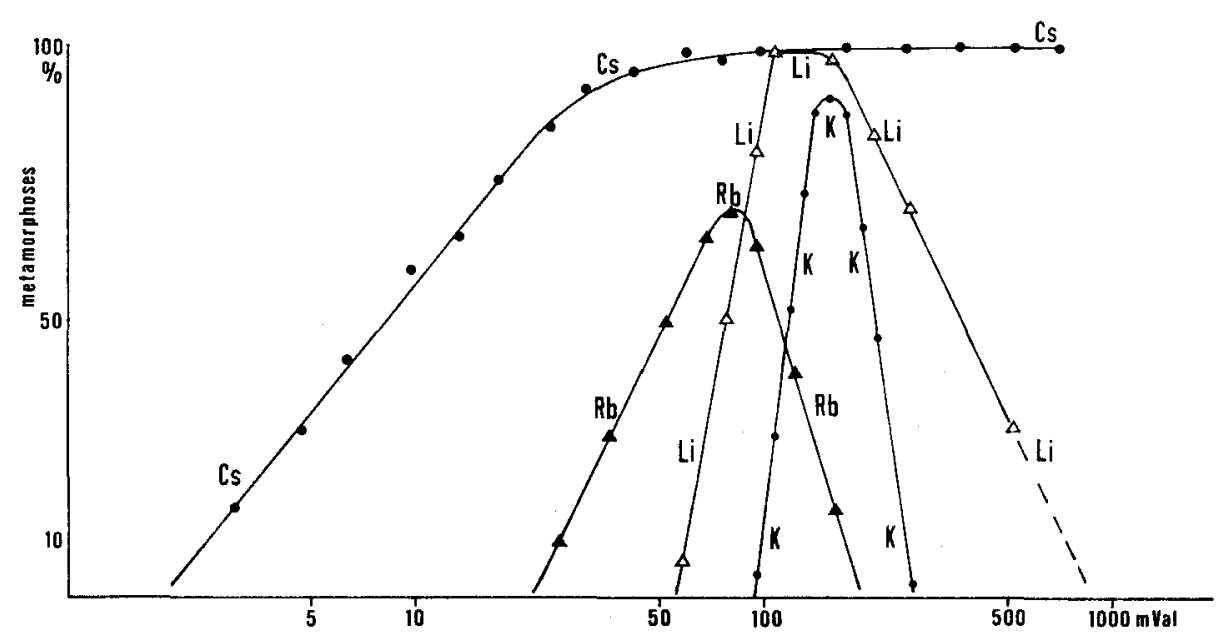

Fig. 3. Dosage-response curves of ion-induced metamorphosis. Semilogarithmic plot.

The ions were tested by mixing seawater with increasing amounts of isoosmolar experimental salt solutions. This procedure, chosen to keep the osmotic value constant, implies necessarily a reduction of the content of the other cations present in seawater. This indicates that the inducing effect is optimal at a distinct ionic balance. Since metamorphosis is heralded by the contraction of the larvae, it followed that we might explore the possible role of calcium.

For this purpose we have made up solutions containing only the ions of calcium and potassium. Osmotic constancy was attained by adding sucrose. Four different calcium concentration were preselected and each calcium level was combined with a series of different potassium concentrations in order to determine the respective optimal ratio (Fig. 4). The results were surprising: Calcium, of course, influences the inducing capacity of potassium. However, the optimal inducing effect was not related to any invariable value of $\left[\mathrm{K}^{+}\right]:\left[\mathrm{Ca}^{++}\right]$. Instead, the optimal ratio varied with the absolute concentrations employed. But when surveying the data it became evident that at the respective optimum peaks a distinct mathematical relation nevertheless always remained constant. Within the physiologically significant range the ratio $\left[\mathrm{K}^{+}\right]: \sqrt{\left[\mathrm{Ca}^{++}\right]}$ was the same regardless of the actual dilution employed. This ratio is exactly the GibBs-Donnan ratio.

The Gibis-Donnan principle concerns the equilibrium established between the ions in the surrounding medium and the ions bound on anionic sites of the surface of 

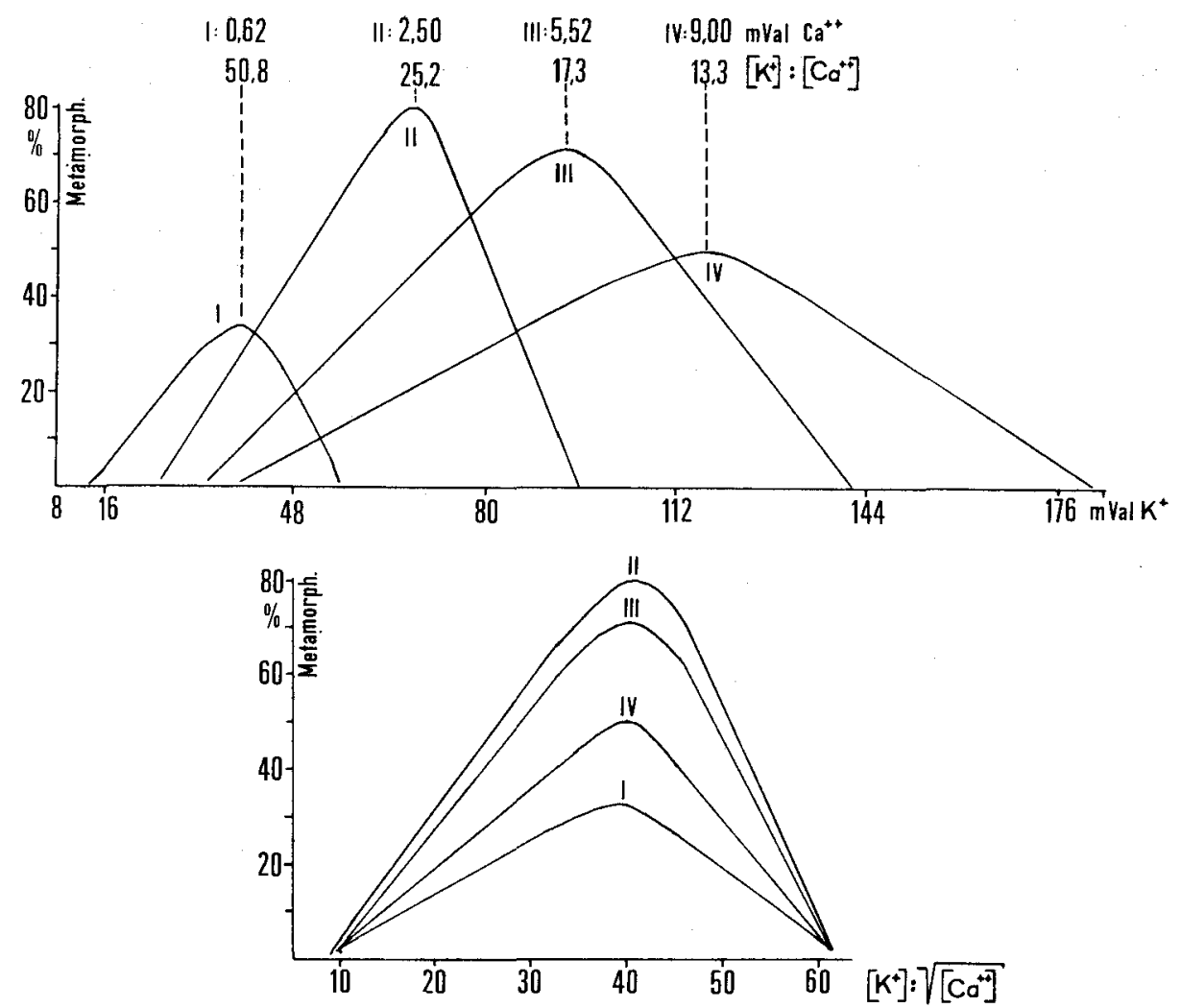

Fig. 4. Influence of external calcium content on the position of the optimum peak in $\mathrm{K}^{+}-$ induced metamorphosis. When plotted against the Gibes-DonNan ratio (figure below) the peaks of the dosage-response curves coincide.

biological membranes. An explanation for this phenomenon can be derived from the LING association-induction theory of bioelectrical phenomena. The significance of this theory in the present context is that the divalent cation controls the binding constants of monovalent cations. These findings gave the first hint that the receptory system receiving the inductive stimulus possesses binding sites for cations and is located in the cell membrane.

But which structure, which component is involved? Let us return to the fact that induction is brought about by the ions of lithium, potassium, rubidium and caesium. A survey of the literature relating to the physiological actions of these ions has drawn my attention to their interaction with membrane bound ATPases. The ions exhibiting inducing power are exactly those which especially affect the sodiumpotassium transport ATPases from a wide variety of sources. This enzyme complex which is bound in the outer cell membrane charges the cell with potassium and extrudes sodium. Thus, this transport ATPase represents the ion-pump generating the electrochemical membrane potential. 

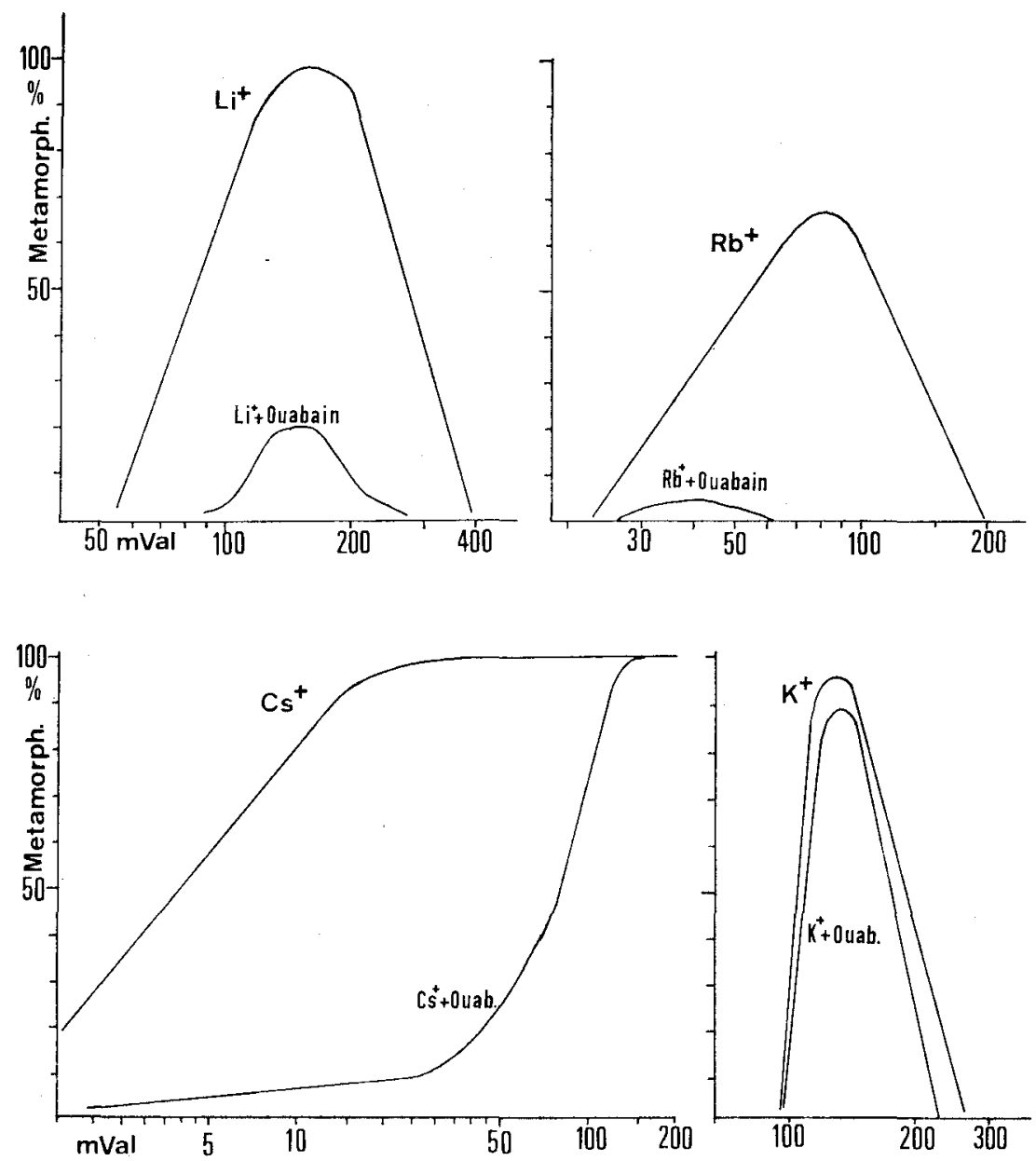

Fig. 5. Reduction of inducing effect by ouabain. Semilogarithmic plots.

It is known that the potassium site of this transport system is less selective than the intracellular sodium-sensitive site. Potassium can be replaced for inward transport in exchange for sodium by lithium, rubidium and caesium (MAIZELS, 1968; BonTING, 1970). Moreover, the potassium carrier in the membrane seems to show a greater affinity for rubidium and caesium than for potassium (KERNAN, 1970).

Indirect evidence that this membrane bound carrier system is indeed involved can be derived from kinetic data. Hypothetically we assume the biological effect, that is successful initiation of metamorphosis, to reflect inflow of potassium and of potassium-substituting ions respectively. Since it is impossible to show all the relevant curves I shall confine the exposition to a brief abstract: Potassium activated induction seems to be based upon a passive event which is controlled by the GiBBs-DonNan principle. But when, at low levels of external potassium, caesium is applied the 
larval response seems to be based upon an active event. The velosity of reaction plotted against the dose displays Michaelis-like saturation kinetics. This indicates the involvement of a carrier system exhibiting properties of an enzyme. Moreover, the properties of this system are similar to the properties of the $\mathrm{Na}^{+} / \mathrm{K}^{+}$-ATPase which controls the exchange of ions in red blood cells (Garrahan, 1970). For example, reduction of the external sodium or calcium concentration will shift the MichaELISMENTEN constant of caesium activation towards lower values. This shift, in turn, gives indirect evidence that the influence exerted by the potassium substituting ion on the cation pump is a stimulating one.

More direct evidence, however, can be deduced from experiments using a specific inhibitor. The cardiac glycoside ouabain (strophantine $\mathrm{G}$ ) is known to inhibit active cation transport by blocking specifically the $\mathrm{Na}^{+} / \mathrm{K}^{+}$-ATPase (BEAUGE and AdragnA, 1971).

Indeed, at sub-maximal concentrations of lithium, rubidium and caesium (but not of potassium) induction is almost completely inhibited (Fig. 5). Treatment of the larvae with ouabain after the ionic pulse had been applied did not prevent the progress of the transformation but rather brought about a slight increase of the number of metamorphosing larvae. The development of ouabain inhibition is antagonized by high concentrations of potassium and potassium-like ions. This applies also to the cation pump in other systems, e.g. red blood cells (MaIzels, 1968, Garrahan, 1970).

Thus, it is justified to assume that the relevant ions act by stimulation of the electrogenic cation pump. But does this apply to the bacterial agent as well? It does!


Fig. 6. Inhibiting influence of ouabain on induction by bacteria and by the isolated inducer. 
Essentially all the action of both the whole bacteria and the isolated agent is abolished by application of ouabain. Conversely, high doses of the isolated leakage material abolish the ouabain inhibition. Thus we reach the conclusion that the bacterial inducer stimulates the activity of the cation pump setting thereby the process of transformation into motion. Unfortunately, the direct determination of the cation stimulated ATPases in planulae requires micro-scale methods which have still to be developed. However, an indirect approach is possible by measuring biochemical activities which are known to be involved in the regulation of cation transport.

In all systems investigated so far, there exists an inverse relationship between the operation of the pentose phosphate pathway and the activity of the cation pump (DiksteIn, 1971). Therefore, we have measured the activities of the two enzymes constituting the pentose shunt (G-6-PDH and 6-PGDH) as compared with enzymes which take a key position in the main ways of carbohydrate metabolism. Some of the results are shown in Fig. 6.

At the onset of metamorphosis the general energy yielding processes, that is

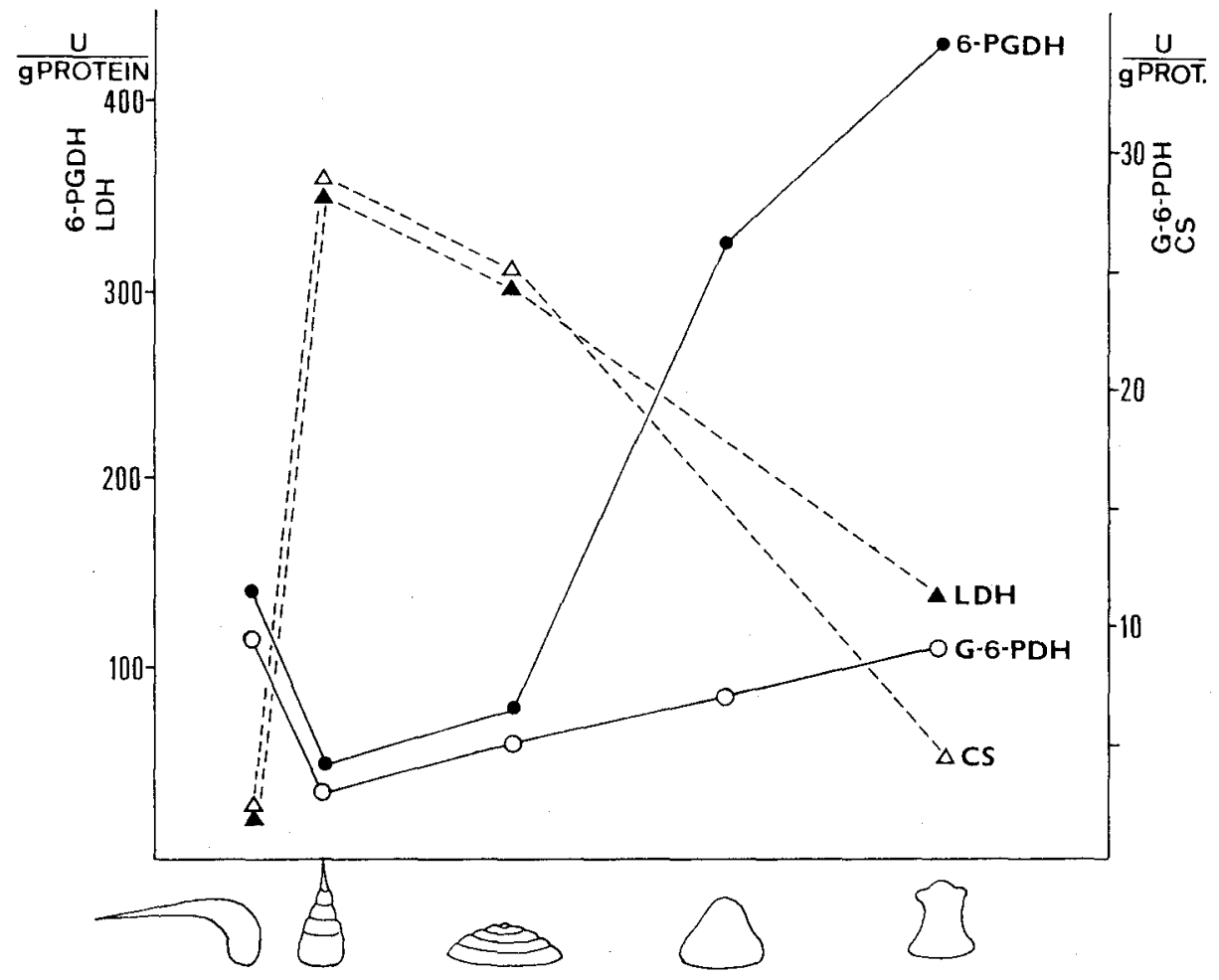

Fig. 7. Activities of enzymes of the pentose shunt (6-phospho-gluconate-dehydrogenase and glucose-6-phosphate-dehydrogenase) during metamorphosis compared with the activities of the condensing enzyme ( $\mathrm{CS}=$ citrate synthetase) and of lactate-dehydrogenase. Measurement according to standard methods. The activity of the cation pump is assumed to be inverse to the operation of the pentose shunt. 
glycolysis and the KREBS cycle, experience an enhanced activation. In contrast to this, the operation of the pentose shunt becomes depressed. In the further progress of transformation, however, the activities of the two relevant enzymes rise again to approach the level of adult polyps. This alteration in turn indicates that only the start of metamorphosis is characterized by an enhanced uptake of potassium. The cation transport ATPase seems to operate only during a brief initiating period which corresponds with the time necessary to incite metamorphosis. Perhaps this may be the reason why both ions and the isolated bacterial inducer must be removed after induction to make possible the further progress of transformation. But why does this not apply to whole living bacteria? Living bacteria do not prevent the further transformation when kept in contact with the animals. Do the bacteria secrete the agent in a pulse-like fashion? I do still not know the answer.

One final remark: One might expect that the activation of the electrogenic cation pump will lead to a change in the membrane potential. Conversely, one might expect that metamorphosis can be induced not only by chemical but also by eletrical stimulation. Preliminary investigations indicate that such expectations may prove to be correct. This hint, however, should only be regarded as indicating that the theme presented here is far from being exhausted. The problems posed in this report comprise ecological, microbiological, embryological, biochemical and even electrophysiological aspects. Thus I hope that this report will persuade others to engage in such investigations as well.

\section{LITERATURE}

Beauge, L.A. and Adragna, N. 1971. The kinetics of ouabain inhibition and the partition of rubidium influx in human red blood cells. J. gen. Physiol. 57, 576-592.

Bonting, S.L. 1970. Sodium-potassium activated adenosinetriphosphatase and cation transport. In: Membranes and Ion Transport, Vol 1, 257-363; ed. by E.E. BITTAR, London, Wiley Interscience.

Buckmire, F.L.A. and MACLeOd, R.A. 1971. Evidence for the release at low salt concentrations of a lipid-proteincarbohydrate complex from isolated envelopes and whole cells of a marine pseudomonad. Canad. J. Microbiol. 17, 713-723.

Dikstern, S. 1971. Stimulability, adenosine triphosphatases and their control by cellular redox processes. Naturwissensch. 58, 439-443.

Garrahan, P.J. 1970. Ion movements in red blood cells. In: Membranes and Ion Transport, Vol. 2, 185-215; ed. by E.E. BITTAR, London, Wiley Interscience.

HeinzelmanN, H., Kraepelin, G. and Bogen, H.J. 1972. Leakage-Produkte von Hefen. Arch. Mikrobiol. 82, 300-310.

HePPEL, L.A. 1967. Selective release of enzymes from bacteria. Science, 156, 1451-1455.

$J_{\mathrm{AHN}}$, T.L. and BoveE, E.C. 1964. Protoplasmic movements and locomotion of protozoa. In: Biochemistry and Physiology of Protozoa, 108-110; ed. by S.H. HutNer, New York, Acad. Press.

Kernan, R.P. 1970. Electrogenic or linked transport. In: Membranes and Ion Transport, Vol 1, 395-429; ed. by E.E. BitTAR, London, Wiley Intrerscience.

Kraepelin, G. 1972. Der Atmungsdefekt der Hefezellen: eine kritische Betrachtung seiner Ur- 
sachen. Z. allg. Mikrobiol. 12, 235-266.

LEwIS, M.J. and PhAFF, H.J. 1964. Release of nitrogenous substances by brewer's yeast. III. Shock excretion of amino acids. J. Bacteriol., 87, 1389-1396.

MaIzels, M. 1968. Effect of sodium content on sodium efflux from human red cells suspended in sodium free media containing potassium, rubidium caesium or lithium chloride. J. Physiol. (London) 195, 657-679.

Müller, W.A. 1961. Untersuchungen zur Ablaichrhythmik des Hydroidpolypen Hydractinia echinata. Zool. Jb., Abt. allg. Zool. u. Physiol. 69, 325-332.

Müller, W.A. 1964. Experimentelle Untersuchungen über Stockentwicklung, Polypendifferenzierung und Sexualchimaeren bei Hydractinia echinata. Wilhelm Roux' Arch. Entwickl.-mech. Org. 155, 181-268.

MÜlLER, W.A. 1969. Auslösung der Metamorphose durch Bakterien bei den Larven von Hydractinia echinata. Zool. Jb. Abt. Anat. 86, 84-95.

Müller, W.A. and SPINDLER, K.D. 1972. The effects of sulphydryl reagents on morphogenesis in hydroids. I. Metamorphosis and regeneration in Hydractinia echinata. Wilhelm Roux' Archiv 170, 152-164.

NeU, H.C. and CHou, J. 1967. Release of surface enzymes in Enterobacteriaceae by osmotic shock. J. Bacteriol. 94, 1934-1945.

Pan, P., Hall, E.M. and Bonner, J.T. 1972. Folic acid as second chemotactic substance in the cellular slime moulds. Nature, New Biology 237, 181-182.

SPINDleR, K.D. and Müller, W.A. 1972. Induction of metamorphosis by bacteria and by a lithium-pulse in the larvae of Hydractinia echinata (Hydrozoa). Wilhelm Roux' Archiv 169, 271-280.

\section{DISCUSSION}

DAN: Have you tried using cyclic-AMP to induce metamorphosis?

Müller: Yes, I have. Cyclic-AMP did not exert any visible effect. But dibutyryl-c-AMP as well as phosphatidyl-ethanolamine extracted from bacteria caused the larvae to engage in longlasting searching movements. These substances, however, did not induce metamorphosis.

THIEL: Do you have any evidence that your results apply to natural conditions as well as to cultural experiments?

MüLLER: I think your question comprises also the question why Hydractinia is most abundantly found on shells of hermit crabs. Let us discuss, therefore, both aspects together.

1) The relevant bacteria are always found on the surface of shells. Pieces of shells are the source from which I usually start isolation. Interestingly enough, the bacteria become effective when bred with small amounts of meat, the natural food of both the crab and the hydroid.

2) Hermit crabs show a behaviour which enhances the probability of an encounter. The crabs often assemble on distinct places. Moreover, when trying to eat the larvae the crabs use to toss the larvae which in turn will attach themselves to the next surface.

3) It might be possible that the oscillations of the shells caused by the movements of the crab is another stimulus initiating metamorphosis. Mr. CAzAux, suggested this. I did not succeed in inciting metamorphosis by pure mechanical stimulation under sterile conditions, but I made the experience that mechanical stimulation will increase the effect of inducing agents.

4) Last but not least, nature uses to select. Larvae which settle on shells of hermit crabs will have better possibilities to survive and to grow. Indeed, one can find Hydractinia on every substratum but those colonies are usually of very small size. Since they lack the characteristic spines and the 
spiral zooids they are often not recognized as being Hydractinia echinata.

SATo: Assume the local gradient of $\mathrm{K}^{+}$ion is responsible to enhance the morphogenesis either directly or indirectly, the capacitance or the conductance of total organism should show correlative change during the process. Would you do any attempt to measure them through the morphogenesis?

MÚlLer: This is one of the next works to be done. Most of the investigations reported here were carried out in the last few months and we recognized the importance of electrophysiological investigations just recently. We are now preparing the devices. 